\title{
Awakening to an Intersectional Reality: Ending the HIV Epidemic in the USA Starts with Reducing Inequities among Black MSM
}

\author{
LaRon E. Nelson
}

Accepted: 8 September 2020 / Published online: 6 October 2020

(C) The New York Academy of Medicine 2020

In 2005, the US Centers for Disease Control and Prevention released data at the National HIV Prevention Conference that Blacks accounted for $46 \%$ of individuals who tested positive for HIV in a five-city epidemiological study of men who have sex with men (MSM) [1]. Furthermore, the report concluded that two-thirds of these Black were unaware that they were living with HIV [1]. It was a moment of Awakening. A group of Black same-gender loving men convened an emergency meeting at a community-based organization in Brooklyn, NY, called People of Color in Criss. This meeting of the Black Gay Research Group (BGRG) brought together Black MSM from across America who were activists, academic researchers, artists, nurses, physicians, social workers, government scientists, community members, and organizational leaders to develop a research strategy that centered indigenously Black gay approaches for both ending the HIV/AIDS epidemic among Black MSM and improving the material conditions and psychological well-being of MSM in Black communities. In 2007, the BGRG, in collaboration with the National Black Gay Men's Advocacy Coalition, released the National Black Gay Research Agenda report developed with support from the New York State Department of Health AIDS Institute and the State of California Department of Health Services Office of AIDS [2]. Since the issuance of the report, the national situation worsened with recent data from the CDC

L. E. Nelson $(\bowtie)$

Yale School of Nursing, Orange, CT, USA

e-mail: laron.nelson@yale.edu estimating that the lifetime risk of HIV infection among Black MSM is 1 in 2 [3]. Today, the USA is in the midst of an ambitious effort to end the HIV epidemic by the year 2030 [4] and the scientific and public health communities understand that in order to achieve this goal for the nation we must better understand and accelerate progress towards ending the epidemic in Black MSM.

The collection of 14 articles in this special issue reflects many of the priority research themes that were selfidentified by the Black MSM community as published in the National Black Gay Research Agenda. This special issue opens with three articles that focus on understanding how social/structural forces operating in local ecological contexts influence HIV. Tieu et al. [5] offer potential pathways by which neighborhood- and network-level factors affect the HIV care continuum for Black MSM while Cassels et al. [6] identified place-related patterns that influenced HIV vulnerability and access to health care among substance-using Black MSM in Los Angeles. Hotton et al. [7] investigated neighborhood-level and socio-structural predictors of criminal justice involvement among MSM in Chicago, which is a particularly salient topic given how the over-policing and criminalization of Black communities hasled to large proportions of Black men being exposed to the criminal justice system. Yang et al. [8] also tackle this phenomenon of criminal justice involvement among African American MSM in Baltimore, its association with transactional sex, and its implications for their re-integration into communities. In Foretelling the Future, Burns et al. [9] identified that an initial diagnosis of gonorrhea and chlamydia predicted subsequent post-cure diagnosis suggesting that 
clinical STI treatment is a critical opportunity to assess and address multi-level behavioral, social, and structural factors influencing HIV vulnerability among Black MSM. Kipke et al. [10] also identified clinical factors influencing HIV risk among Black and Latino MSM in the context of larger social and structural determinants, including intersecting racism and homophobia. Brooks et al. [11] bring a focused understanding on the multiple levels (family-level, medical provider-level) of intersecting pre-exposure prophylaxis (PrEP) stigma and gay stigma experienced by Black MSM that must be addressed in order to optimize PrEP implementation and impact on the epidemic. Five of the articles in this special issue examined sociocultural assets among Black MSM - offering evidence to inform intervention strategies that buffer against intersectional stigmas and other oppressive social processes. In the White et al. [12] study of Black MSM in Baltimore, membership in the house and ballroom community and having a larger number of network members living with HIV were both associated with high self-efficacy of communicating with peers regarding men's health issues. Using data from the largest domestic prospective cohort study of Black MSM (HPTN 061)—drawn from six cities (i.e., Atlanta, Boston, Los Angeles, New York, San Francisco, Washington DC) - Okafaor et al. [13] found that most participants living with HIV communicated their status to their last male sex partner and that disclosure was associated with lower odds of condomless receptive anal intercourse with an HIV serodiscordant or HIV status unknown partner. The positive role of social support on HIV prevention and treatment engagement is highlighted across four articles - including the value of spiritual/religious support [14], support from parental figures [7, 14, 15], peer support [14-16], and the salience of transgender women in the social support networks of Black MSM $[15,16]$. Finally, Robbins et al. [17] identify trends among adolescent sexual minority men between alcohol/substance use and behaviors that may increase their likelihood of exposure to HIV while Gordían-Arroyo et al. [18] round out the issue identifying the opportunity for PrEP implementation with their evidence of high awareness and willingness to use PrEP among a mostly Black and multi-racial sample of adolescent sexual minority men drawn from across the USA.

The papers in this special issue represent important scientific progress on key areas identified nearly over a decade ago in a Brooklyn, NY, storefront community organization. The evidence compiled here offers directions that can be used by the research community, healthcare service providers, program implementers, and government agencies to accelerate progress towards the current national goal of ending the HIV epidemic by 2030.

\section{References}

1. Centers for Disease Control and Prevention. HIV prevalence, unrecognized infection, and HIV testing among men who have sex with men-five US cities, June 2004-April 2005. Morb Mortal Wkly Rep. 2005;54:597-601.

2. Black Gay Research Group. A national black gay research agenda. 2007. Available online at http://naesm.org/wpcontent/uploads/2020/09/BGRG-Research-Agenda-7.pdf. Accessed 27 Sep 2020.

3. Hess KL, Hu X, Lansky A, Mermin J, Hall HI. Lifetime risk of a diagnosis of HIV infection in the United States. Ann Epidemiol. 2017;27(4):238-43. https://doi.org/10.1016/j. annepidem.2017.02.003.

4. Giroir BP. The time is now to end the HIV epidemic. Am J Pub Health. 2020;110(1):22-24.

5. Tieu H, Koblin B, Latkin C, Curriero F Greene E, Rundle A, Frye V. Neighborhood and network characteristics and the HIV care continuum among gay, bisexual and other men who have sex with men. J Urban Health. 2020; (this issue).

6. Cassels S, Meltzer D, Loustalot C, Ragsdale A, Shoptaw S, Gorbach P. Geographic mobility, place attachment and the changing geography of sex among mostly minority MSM who use substances in Los Angeles. J Urban Health. 2020; (this issue).

7. Hotton AL, Cheng YT, Schumm P, Khanna AS, Brewer R, Skatthun B, Issema RS, Ramani S, Ramachandran A, Ozik J, Fujimoto K, Harawa N, Schneider JA. Socio-structural and neighborhood predictors of incident criminal justice involvement in a population-based cohort of young Black MSM and transgender women. J Urban Health. 2020; (this issue).

8. Yang C, Zaller N, Clyde C, Tobin K, Latkin C. Association between criminal justice involvement and transactional sex among African American men who have sex with men in Baltimore. J Urban Health. 2020; (this issue).

9. Burns P, Mena LA, Crosby RL. Foretelling the future: predicting STI diagnosis and its implications for ending the HIV epidemic among black men who have sex with men. J Urban Health. 2020; (this issue)

10. Kipke MD, Kubicek K Akinyemi IC, Hawkins W, Belzer M, Bhandari S, Bray BC. The healthy young men's cohort: stress and risk profile of black and Latino young men who have sex with men. J Urban Health. 2020; (this issue).

11. White JJ, Yang C, Tobin KE, Beyrer C, Latkin CA. Individual and social network factors associated with high self-efficacy of communicating about men's health issues 
with peers among black MSM in an urban setting. J Urban Health. 2020; (this issue).

12. Brooks RA, Nieto O, Landrian A, Feherenbacher A, Cabral A. Experiences of pre-exposure prophylaxis (PrEP)-related stigma among black MSM in Los Angeles. J Urban Health. 2020; (this issue).

13. Okafaor CN, Li M, Hucks-Ortiz C, Mayer KH, Shoptaw S. Disclosure of HIV status and HIV sexual transmission behaviors among HIV-positive black men who have sex with men in the BROTHERS (HPTN 061) study. J Urban Health. 2020; (this issue).

14. Greib SM, Donovan E, White JJ, Miller D, Dangerfield DT. Increasing opportunities for spiritual and religious supports to improve HIV-related outcomes for Black sexual minority men. J Urban Health. 2020; (this issue).

15. Lelutiu-Weinberger C, Koblin B, Wilton L, Hoover D, Hirshfield S, Chiasson MA, Nandi V, Usher D, Frye V. The role of social support in HIV testing and PrEP awareness among young black men and transgender women who have sex with men or transgender women. J Urban Health. 2020; (this issue).
16. Chen Y, Duncan DT, Issema R, Goedel WC, Callander D, Bernard-Herman B, Hanson H, Eavou R, Schneider J, Hotton A. Social-environmental resilience, PrEP uptake, and viral suppressions among young black men who have sex with men and young black transgender women: the neighborhoods and networks (N2) study in Chicago. J Urban Health. 2020;(this issue).

17. Robbins T, Wejnert C, Balaji AB, Hoots B, Paz-Bailey G, Bradley H. for the NHBS-YMSM Study Group. Binge drinking, non-injection drug use, and sexual risk behaviors among adolescent sexual minority males, 3 US cities, 2015. J Urban Health. 2020; (this issue).

18. Gordián-Arroyo A, Garofalo R, Kuhns LM, Bruce J, Batey DS, Radix A, Belkind U, Hidalgo MA, Hirshfield S, Schrimshaw EW, Schnall R. Awareness, willingness, and perceived efficacy of pre-exposure prophylaxis among sexual minority males. J Urban Health. 2020;(this issue).

Publisher's Note Springer Nature remains neutral with regard to jurisdictional claims in published maps and institutional affiliations. 